\title{
KEY TRENDS AND ASPECTS INFLUENCING CHANGES INTO SPATIAL PLANNING SYSTEMS AND PRACTICES IN EUROPE
}

\author{
Armands Auzinš ${ }^{\prime \prime}$ Dr.oec. \\ ${ }^{1}$ Institute of Civil Engineering and Real Estate Economics, FEEM, Riga Technical University
}

\begin{abstract}
More than a decade ago the Territorial Agenda (TA) of the EU aimed strengthening territorial cohesion and was built upon three main aims of the European Spatial Development Perspective (ESDP), thus of European planning. Since then different integrated tools for European spatial development have been proposed and instruments based on various initiatives to support spatial planning practices created. New TA under the specific objective enhanced European territorial evidence gathering through applied research and analyses. Recent comparative studies of territorial governance and spatial planning systems and practices emphasised meaningful changes, their influences and possible further continuity. Latvia, along with other Baltic States, over the past two decades has witnessed considerable changes in institutional settings of spatial planning system and planning practice as well. The aim of the study is to explore the key trends and aspects which have influenced changes into spatial planning systems and practices in Europe. The review of scientific literature as well as dynamic and comparative analysis and synthesis techniques have mainly been employed for the study. The main outcome of the research shows that reforms, economic crisis and restructuring as well as institutional arrangements, challenges of globalization and 'Europeanization' of spatial planning agendas basically influenced changes into planning systems and practices, which explains its continuation and a potential for introduction of advanced planning approaches.
\end{abstract}

Key words: spatial planning systems, practices, comparative analysis, Territorial Cohesion, Europe. JEL code: 021 , R58

\section{Introduction}

European countries over the past two decades have witnessed considerable changes in institutional settings and governing structures of spatial planning systems as well as in planning practices and even in discourses. During the evolution of these changes, several spatially relevant policies, i.e. European spatial planning (ESDP, Territorial Agenda) and regional policy (ERDF, ESF, Cohesion Fund), have been provided. The TA of the EU (TA 2007) aimed strengthening territorial cohesion and was built upon three main aims of the ESDP, thus of European spatial planning: (1) polycentric development and urban-rural partnership, (2) access to infrastructure and knowledge, (3) sustainable development and prudent management of the natural and cultural resources (European Commission, 2007). Under the European Spatial Planning Observation Network (ESPON) project, the integrated tools for European spatial development have been intended to apply (Faludi A., 2008). The paradigm of "Europeanization of spatial planning" may be seen as consequence from introduction of Territorial Agenda and European influence on planning systems. Thus, this paradigm could be perceived twofold: planning systems in Europe or Europe for planning systems. 'Europeanization', understood either as governance, institutionalization or discourse, introduced different mechanisms and modes of governance: hierarchy, bargaining and facilitated coordination (Radelli C. M., 2004). How domestic institutions assimilate new challenges driven by 'Europeanization'? Therefore, particular attention is paid to the extent to which the process of 'Europeanization' is leading to the convergence or divergence of planning systems (Reimer M. et. al., 2014). The creation of instruments for European planning is topical and based on various intergovernmental and community initiatives (Faludi A., 2008). Nevertheless, a discursive integration of European spatial planning agenda at national level can be found in ESDP arguments for an integrated way of spatial planning, regional economic development as well as environmental and cultural development. New TA (TA 2020) under the specific objective of the ESPON 2020 
Cooperation Programme, "Enhanced European territorial evidence production through applied research and analyses", applied research projects to contribute to the European territorial and analytical evidence base. As territorial governance and spatial planning systems have now evolved to become one of the key components of integrated cross-sectoral development strategies and policy delivery mechanisms among ESPON member and partner states, the comparative analysis of territorial governance and spatial planning systems in Europe is being performed (ESPON EGTC 2020).

However, recent comparative research (Reimer M. et. al., 2014) delineated the coexistence of continuity and change and of convergence and divergence with regard to spatial planning practices across Europe (case studies and comparative conclusions of 12 countries) based on a systematic and methodological framework for analysing changes in planning systems and practices. Thus, a specific and context-dependent variety and disparateness of 'planning transformation' have been proposed to focus on. Therefore, it is recognised that by using proposed methodological framework, the systems and practices in all other European, i.e. in Baltic States should be studied and key trends and aspects analysed. If considering similar historical evolution of three Baltic States - Estonia, Latvia, and Lithuania, it should be necessary to develop a model of transformation design and to explain main phases and turning points when setting a time perspective by years since the restoration of independence in 1990s. Therefore, more complete study outcome due to 'path-dependent evolutions' could be designed and discussed.

If considering above described topicality and quite challenging issues, the author of the research proposed a hypothesis - there exist several other driving forces apart of 'Europeanization' causing changes into European spatial planning practices and discourses. The aim of the study resulting from the drawn hypothesis is to explore the key trends and aspects which have influenced changes into spatial planning systems and practices in selected European countries, including Latvia. The objectives of the study to meet the aim are: (1) to identify the key trends and aspects influencing changes into spatial planning systems and practices based on profound literature review; (2) to analyse the outcome of comparative studies by using previously developed methodological framework and established criteria; and (3) to explore the evolution of Latvian spatial planning experience and to discuss it in the light of previously made comparative studies, which presents a novelty of the research. The following research methods have been employed for the study: the review of scientific literature and legal instruments; the expert interview method; the dynamic and comparative analysis and synthesis techniques.

\section{Research results and discussion}

The Commission of the European Communities issued "The EU Compendium of Spatial Planning Systems and Policies" in 1997, which gave some overview about spatial planning systems and traditions of 15 European Member States as well as enabled to understand these systems in operation and identified four 'ideal types' (CEC, 1997). Considering these types, M. Reimer et. al. (2014) selected 12 countries for comparative analysis. Each one of the countries represented some of those types/traditions. Accordingly, Denmark, Finland, the Netherlands, and Poland represented a "comprehensive/integrated" planning tradition, Germany represented partly both "comprehensive/integrated" and "regional-economic" planning traditions, France represented a "regional-economic" planning tradition, Italy, Greece and Turkey represented the tradition of 
"urbanism", but Flanders/Belgium and the United Kingdom represented a "land-use management" planning tradition.

Different contexts of changes were demonstrated in 'country chapters', which more properly emphasise those under particular circumstances: legal and institutional changes of the system, including changes in scope, planning tools and the role of actors at different levels, as well as discussions and discourses emerging from these changes (in general and Denmark), development of the planning system by considering the city as a part of metropolitan region and as best its reflection (Finland), national spatial planning at the end of an era (the Netherlands), institutional inertia and new challenges (Germany), drifting away from the "regional economic" approach/ideal type in planning (France), modernization and trajectories of innovation of the planning system (Italy), mainstream planning and the potential offered by strategic planning obscured by privatization of planning powers and services, as well as outsourcing of pro-growth planning as consequence of economic crisis (Greece), demonstration of institutional dynamics of very long period of time (after 1945) as a background for challenges for spatial structure planning (Flanders), evolution of spatial planning through three waves of reform (the UK), step-by-step evolution/mainstream (the Czech Republic), national-historical (Turkey), planning between dominant market forces and European influence (Poland). Latvia, the same as the Czech Republic and Poland, faced a transition from planned economy in post-soviet space and incremental development of market economy to effect of European spatial planning agenda till now.

Referencing to the study (Reimer M. et. al., 2014), three criteria have been set to most properly characterise key trends and aspects influencing changes into and thus transformation of spatial planning systems and practices in selected European countries and in Latvia.

\section{The scope and main objectives of changes.}

O. Damsgaard described decentralization and re-centralization processes, which after 2007 facilitated in the way the power and planning tasks of counties largely subdivided between municipalities and the state in Denmark (Reimer M. et. al., 2014, pp. 21-41). Early signs of recentralization were recently seen regarding large-scale retail projects by S. Hirvonen-Kantola and R. Mantysalo. They also emphasised economic restructuring due to deindustrialisation and globalisation challenges in Finland (Reimer M. et. al., 2014, pp. 42-60). G. Erkut and E. Sezgin recognised trends towards decentralization and re-centralization at the same time, thus decentralization of planning to the local level, but in case of some tools evaluated as recentralization in Turkey (Reimer M. et. al., 2014, pp. 236-254). W. Zonneveld and D. Evers showed clearly how the economic development has become the main priority in Dutch spatial planning (Reimer M. et. al., 2014, pp. 64-82). However, the land policy towards reducing the increase in sealed surfaces, e.g. open space for settlement and transport purposes, was designed in Germany and characterised by H. H. Blotevogel et.al. (Reimer M. et. al., 2014, pp. 83-108). Moreover, modern territorial governance there appeared through combining both hard and soft modes of control of spatial planning and development. Thus, it was declared: "soft forms of communication and consensus building as much as possible, hard forms of binding goals and hierarchical control as much as necessary" in Germany. It may be generally concluded that dimensions and directions of changes are not linear and show multiple trajectories in all countries. However, A. Geppert emphasised constituted decentralization in 2003, as well as introduction of strategic dimension in statutory planning, however pointed to the need for more dynamic and process-oriented planning 
methods in France (Reimer M. et. al., 2014, pp. 109-126). P. Getimis and G. Giannakourou argued for the 'privatization' of public functions/powers of planning, which consequently enabled a progrowth planning, and so more flexible and market-oriented types of planning during economic crisis 2010-2012 in Greece (Reimer M. et. al., 2014, pp. 149-168). P. Van den Broeck et.al. pointed to shifting towards market- and property-oriented policies after 1999 and need for urban restructuring and instruments of project-oriented urban design in Flanders (Reimer M. et. al., 2014, pp. 169-188). V. Nadin and D. Stead identified the attempt to change the culture of planning from primarily land-use regulation to embrace a more strategic approach in the UK (Reimer M. et. al., 2014, pp. 189-214). K. Maier argued that the priorities in planning changed from control spatial allocation of investments till enforcement of public infrastructure projects and grounding development in the Czech Republic (Reimer M. et. al., 2014, pp. 215-235). G. Cotella described progressively reformed territorial governance activities and indicated promotion of neoliberal economic approach as prerequisite for enabling foreign investments in Poland (Reimer M. et. al., 2014, pp. 255-277). Likewise as in the case of Poland, also in Latvia were progressively reformed territorial governance activities through subsequent legal amendments and changes in planning system. Furthermore, neoliberal economic approach was fostered for enabling to plan demand-driven territories for a development.

\section{The driving forces causing changes and main phases and turning points.}

Different main driving forces influenced changes in observed European countries over past two decades and specified in 'country chapters' by the authors of the comparative study (Reimer M. et. al., 2014). These forces are: changes in administrative structure and the regions have lost their spatial planning influence in Denmark (high degree of continuity up to 2000, a reform of local government structure in 2007, changes in regional planning after 2007, impact of the financial crisis 2008-2009, less liberal directions in planning rules after 2012); institutional ambiguity, the competition between municipalities and sustainable development agenda in Finland (lack of planning cooperation in urban regions, deep economic recession of the early 1990s, intensified migration of unemployment, competition for investments, sustainable development principle in legislation); economic development as main priority of spatial planning in the Netherlands (institutional environment of national spatial planning has transformed fundamentally since the early 1990s, regional economic policy has become as the main spatial policy trust, Spatial Planning Act 2008 stimulated proactive planning and urban growth); experimental and successful combination of formal and informal planning modes to deal with significant challenges in Germany (Concepts and Strategies for Spatial Development in Germany 2006, the structural weakness of the traditional planning system makes informal planning processes seem particularly attractive, experimental forms of planning activity are being tested, general trend towards the municipalisation of regional planning, "regional governance" as new pattern of control, European integration and globalisation are leading to intensified locational competition); deep transformations of the institutional settings and intensive sequence of large reforms in France (transformations and reforms 1995-2010, social diversity and inclusion initiative at municipal level since 2000, knowledge economy from European discourse, economic crisis in 2008 activated a support for economic sectors, globalisation and international competitiveness); administrative reform and trend towards a reform of planning system in Italy (subsidiarity-oriented administrative reform 1997-1999, the consequent regionalisation of planning competences, natural emergencies 
transformed into disasters, deliberative emergencies, e.g. 'housing emergence'); strategic planning approach caused EU discourse and changed with economic crisis after 2010 in Greece (uncontrolled urban sprawl, illegal possession and developments, pollution, lack of public space degradation, land-use conflicts, environmental problems 1990s and 2000s, EU pressure, EU financed programs and EC initiatives); the political changes caused changes in planning system in Flanders (predominance of the planning permit system and the rise of urban design before 1991, political change in 1991, spatial structure planning on the political agenda, fragmentation and bureaucratisation of structure planning after 1999); three waves of reform in the UK (plan-led planning approach in the 1990s, environmental protection and sustainability agenda in the 2000s, accent on localism, neighbourhood planning from 2010); administrative reform and EU accession process in Turkey (reform, devolution, privatization, neoliberal political agenda, globalization, Marmara earthquake and Helsinki Summit in 1999, promotion of EU pre-accession funds and investment after 2000); transition to and development of market economy and 'Europeanization' in the Czech Republic (territorial disparities as side effects of transformation and privatisation, sub-urbanisation and urban sprawl increased alongside with liberalism, fragmentation of landscape, pre-accession arrangements, an increasing influence of globalisation and economic crisis), in Poland (administrative reform in 1999, increasing influence of foreign investors, re-institutionalised planning framework in 2003, growing influence of EU, pre-accession period with financial measures, 'Europeanization' of spatial planning), in Latvia (land reform since 1990, gradual development of market economy and increasing influence of foreign investors 1994-2004, administrative-territorial reform and economic crisis 2008-2009, 'Europeanization' of spatial planning, incremental urban development, improved planning practice after 2011).

\section{Policy, planning styles and tools.}

Referencing to the comparative study (Reimer M. et. al., 2014) and, in particular, to the 'country chapters' accomplished by the authors, who presented specific cases of the study, the key trends and aspects of various policies, spatial planning styles and tools were explored. In Denmark, the planning system has evolved from a traditional, top-down coordinated land-use system to a bottom-up oriented system. Today, the municipal level is the most important, however, the system has become more fragmented and heterogeneous (growing variations between municipalities). The economic, social and political context has changed dramatically. From 2000 onwards the concept of municipal planning strategies was introduced, local spatial plans and detailed plans carried out for development. The role of new regional spatial plans is rather to function as a vision and inspiration for regional development. National planning developed due to two different trajectories - very traditional physical function mode and partnership direction and further regional development. In Finland, the spatial planning system is a normative and multilevel system based on land-use planning. Hierarchical system exists, in which general planning ideally guides detailed planning and aims to produce legally binding plans and enable development and implementation. National planning has been reformed since 1990s. Decentralization gave substantially more power to the municipalities in decision-making regarding land-use planning; however, actual planning practice seldom conforms to the formal planning hierarchy. Landowner rights (a basic building right) are exceptionally well protected by the law. National land-use guidelines are advisory, regional plans binding, master plans are optional, but detailed plans are binding. In the Netherlands, after 1990s almost perfect example of a comprehensive integrated 
approach was gradually replaced by a kind of regional economic approach at the national level. Provinces and municipalities are given responsibility for urbanization. Planning focuses on the economically most competitive parts of the country. Different planning cultures even at the provincial and municipal levels exist. There is no clear-cut hierarchy defined by a binding national plan, as well as lower levels of government re-interpret the plans and policies of higher levels of government. Consultations and negotiations are the key to the planning process, and strongly recall the Dutch tradition of 'polderen'. Local land-use plans are legally binding. The combination of spatial planning and economic policy focuses on strengthening the competitiveness of the country that has been the predominant goal of spatial policy. In Germany, a decentralized, multi-level system exists, which is rendered very complex by the federal structure of the country. Hierarchically structured system influenced by three principles: subsidiarity, municipal planning autonomy, and mutual feedback from other planning levels. Many conflicts can be solved with informal types of inter-municipal cooperation. Spatial planning has become more strategic, and at the same time, more communicative and networked. Significant informal planning instruments applied also for the implementation of formal planning. Nowadays, both hard and soft modes of control are combined with one another as modern territorial governance. Legally binding plans and supplementary tools for the safeguarding and implementing of spatial planning norms often amended, but continue to exist. Planning is not become ineffective, but its traditional tools are insufficiently suitable. A regional land use plan has been introduced for distinguished cities. In France, the spatial planning system is hybrid, somewhere between the regional economic and comprehensive integrated approaches. Shortcomings of the system related to the unclear governance patterns. Today, soft granted spaces cover almost all territory of the country. Public participation is rather low in the culture, as well as transparency of public decisions, the use of public funds, and the collaboration within PPP is rather big challenge. State administration played a dominant role at the local level in statutory planning, land-use management and implementation of large projects. However, drifting away from this approach can be seen in vertical and horizontal cooperation, policy integration, multi-actor and multi-level cooperation increased, better coherence of planning documents can be identified. Accordingly, new requirements have been addressed to planners and traditional planning tools become more strategic and soft spatial planning entered into planning practice. In Italy, the concept of planning as a public function of local administration exists. The introduction of more flexible instruments and of shared decision-making processes based on the direct involvement of private stakeholders may be seen as innovation. The shift from "urban planning" to "spatial planning" concept as well as growing awareness of strategic spatial planning can be highlighted. Cross-border areas as territorial platforms for implementation of territorial cooperation strategies have been determined. Complex urban programs are developed, as well as experimental applications of strategic planning methodology practiced and altogether facilitated horizontal cooperation. Planning system operates in which a master plan has both a structural level and an operational level, including land-use regulation. In Greece, high degree of centrality of the planning system, hierarchical, formal and legalistic apparatus of spatial regulation exist. Rigid regulations implemented, but reality does not necessarily comply with them. Controloriented policy style with central, regional and local levels of territorial administration is recognised. However, a parallel shift towards strategic spatial planning and more participatory approach took place in the late 1990s. Planning agenda already since 1990 s and in 2000 s emphasised the role of strategic spatial planning in promoting sustainability along with the need to accelerate big 
infrastructure projects. Master planning for all large urban centres and integrated urban plans for urban areas are carried out. However, planning practice has been unable to generate trust between state, society and the market as well as to guide planning procedures in a more consensual direction. In Flanders/Belgium, different groups have re-produced different, sometimes competing, planning systems, e.g. the planning permit system, spatial structure planning, land-use planning, infrastructure planning, project planning, environmental planning. Flemish structure planning and land-use planning have been reoriented towards the protection of private property. Spatial planning system historically evolved from land-use planning to spatial structure planning and back. Changes into 2000s favoured the further development of the gentrification and project-oriented urbanistic approach, thus spatial structure plans changed in order to increase local economic development possibilities. In the UK, the Anglo-Saxon neoliberal social model related to the collection of shared values in a society operates. Liberal stream of a society with a strong emphasis on individual responsibility and long history of PPP exist. Land-use regulation feature has been dominant. Planning changed from plan-led system in the early 1990 s, to spatial planning approach late 1990s, and neighbourhood planning from 2010. Comprehensive regulation of land-use and development has been introduced. Local development plans must be in conformity with national policies. Plans are not legally binding nor are they detailed in the form of zoning plans, but use more performance criteria. System employs legally binding zoning plans. Value capture duties associated with approvals to develop have been introduced and locally negotiated agreements have been widely used for recoupling betterment. The profession of planner focuses on negotiations much. In the Czech Republic, the strong initial position of communities existed and spatial planning was responsibility of local self-governments since 1990. Planning at municipal level was quite fragmented and it was transferred to regional administrations in 2003. EU standards were adjusted and, currently, the planning system is a conglomeration of different approaches: urbanism, landuse management, and comprehensive planning at the regional and national levels; however, regional policy inspired from regional economics. Planning practice becomes more conservative as it remains based on 'values-free' role (executive arm) of a planner. Planning instruments are clearly defined, updated and well coordinated. The upper tiers being binding for lower tiers of plans. Development-oriented planning practice dominates. However, the planning values are analysed and required for local plans. In Turkey, planning practices are piecemeal and weak coordination between authorities exists in spite of centralised coordination since 2011. Trends towards decentralization and re-centralization at the same time have been identified. The planning system is trying to find ways to cope with new problems and challenges. Privatisation and related project-based planning activities are proceeded. A hierarchical, statutory planning system is responsible for land-use planning and development control. Regional plans produced by established agency and environmental plans produced by regional or governmental administrations, but development plans and implementation plans produced by municipalities. Regional plans are not binding and are more oriented towards economic development. New law on "Urbanization and Planning" issued for coordinating and harmonising the planning system. The way towards strategic spatial planning approach and communicative planning has been taken. In Poland, neoliberal macro-economic approach called for a revival of regional policy and the reintroduction of spatial planning at the national level. However, the fracture between national and regional strategies existed as well as a strong fracture still persists between national priorities/European discourses and local planning and development practices. Weak civic sector and limited community 
participation in planning that powers private investors. Despite of reforms and institutional changes, a strong limitation of municipal planning activities exists. Planning merely strategic than prescriptive and regulative. Cities practice entrepreneurial approach to spatial development. "Spatial and Territorial Development Act" (2003) introduced the responsibility of regional selfgovernment over development strategy and development plan; however a local spatial development plan has binding regulations on the territory.

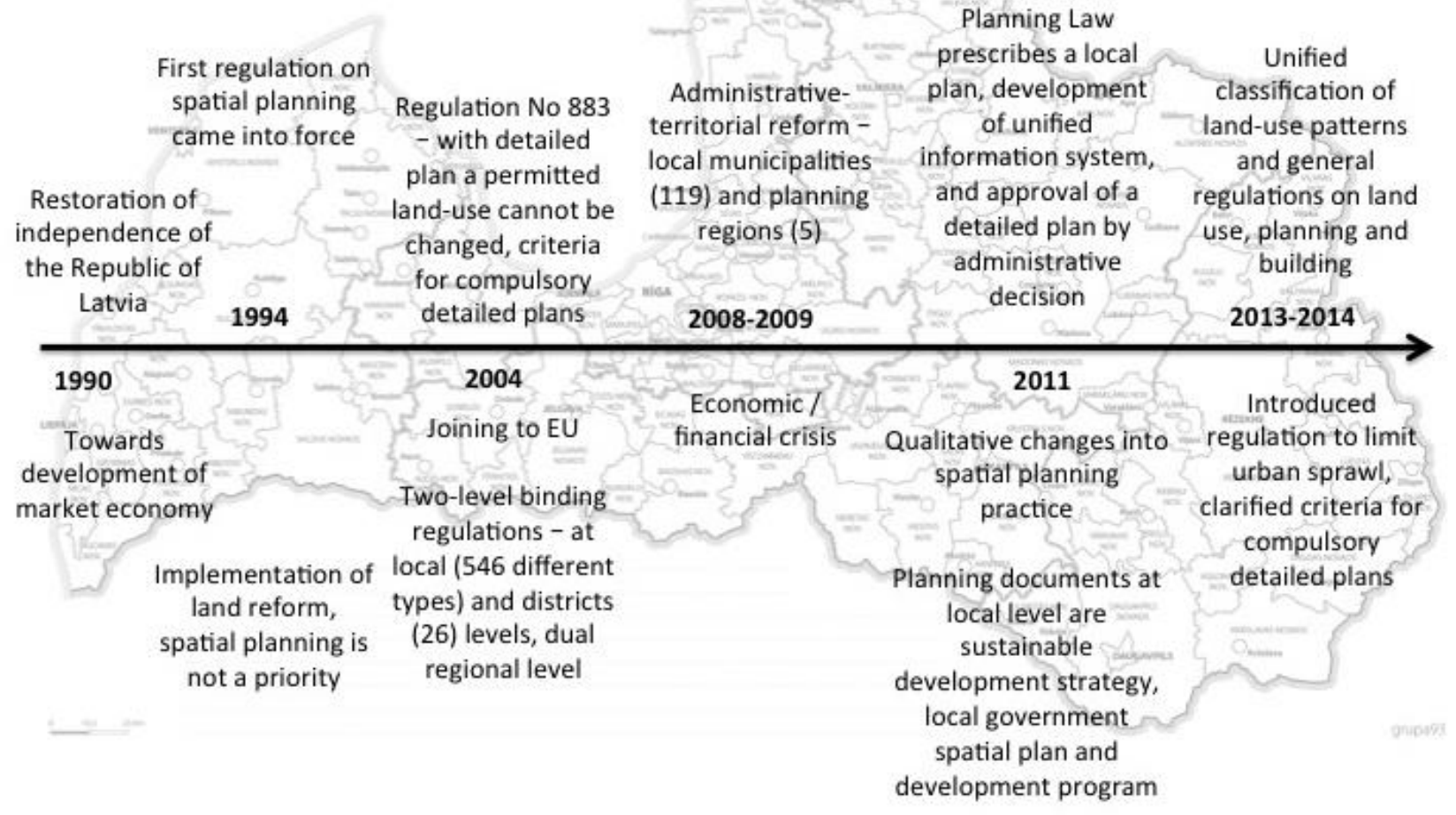

Source: author's design based on outcome of empirical research

\section{Fig. 1. The evolution of spatial planning in Latvia}

Inspired by profoundly conducted comparative study of Reimer M. et. al. (2014), the key trends and aspects of Latvian policies, spatial planning styles and tools have been explored and in more detailed way are discussed by author here. In Latvia, initially (since 1990), the priority was given to implementation of land reform, which delayed establishment of first institutional settings (in 1994) for spatial planning. Spatial planning system and practice developed gradually with significant changes in institutional settings in 2004 and 2011. "Spatial Development Planning Law" (2011) determined new institutional settings for spatial planning agenda and aimed qualitative changes into spatial planning practice. Since then the shift towards strategic spatial planning approach can be argued, as all three planning levels (national, regional and local) have strategies. Since administrative-territorial reform (2009) a physical planning with legally binding parts of local governmental plan has been practiced. The planning style can be characterised as decentralized, integrated and comprehensive spatial planning with a tendency of centralization for recognising the priorities of national and regional scales. Weak cooperation among stakeholders, public activity and participation increases slowly. The author agrees with the arguments provided by N. Adams, that Baltic States reflect a 'culture of pragmatism' in spatial development planning (Adams $\mathrm{N}$. et. al., 2014). Meanwhile, the qualitative improvement of planning practice can be seen since 2013, thus differences into design of local development plans among municipalities are limited and 
application of GIS solutions for planning are promoted. Statutory planning exists only at local/municipal level, thus local government spatial plans (comprehensive plans), local plans and detailed plans are elaborated. Additionally, the planning documents at local level are concerned with a sustainable development strategy and development program. National and regional levels have guiding development strategies. Figure 1 shows the evolution of spatial planning system including main phases and turning points since 1990.

\section{Conclusions, proposals, recommendations}

1) Planning functions changed from the blueprint master planning early 1990s (e.g. general planning in Latvia), to regulative, strategic, and informative functions that is becoming an important complement to the legal power of statutory plans as well as the indicative importance of development strategies and informal planning approaches. Globalization and international competition foster neoliberal approaches-oriented towards territorial competitiveness. The scope of planning has broadened from physical planning to institutional design and the methods have evolved from quite static (e.g. land-use zoning) to dynamic, process-oriented. The planning systems are heterogeneous, some systems shifted from CEC 'ideal types', and practices developed differently.

2) Reforms, economic crisis and restructuring as well as institutional arrangements, challenges of globalization and 'Europeanization' of spatial planning agendas basically influenced changes into planning systems and practices, which explains its continuation and a potential for introduction of advanced planning approaches. Financial/economic crisis influenced all planning systems and practices, but mostly in relation to implementation processes at local land management level. It is emphasised and reflected by country cases (Latvia, Greece, France, Denmark). Accordingly, the proposed hypothesis has been tested and it confirmed, as there exist several other driving forces apart of 'Europeanization' causing changes into European spatial planning practices and discourses.

3) It may be generally concluded that dimensions and directions of changes are not linear and show multiple trajectories in all observed countries. The principle of sustainable development exists in every planning system, but it differently (in distinguished contexts) appears in planning practice.

4) The introduction of more strategic planning practice has been initiated. Further challenges for planning discourse are related to rural-urban linkage, urban settlements and its agglomerative areas, demographic change and migration. Therefore, some initiatives towards informal (complementary) planning mode and related tools could be of great significance. The projectoriented approach shows some experiences in planning as a bundle of instruments.

5) If considering the evolution, changes and continuity of spatial planning systems and practices in observed European countries, it is concluded, that Latvian spatial development planning approach, in general, has been developed as a comprehensive integrated and land-useoriented, which is more similar with such Nordic countries as Denmark and Sweden.

\section{Acknowledgement}

This work has been supported by the European Regional Development Fund within the Activity 1.1.1.2 "Post-doctoral Research Aid" of the Specific Aid Objective 1.1.1 "To increase the research and innovative capacity of scientific institutions of Latvia and the ability to attract external 
financing, investing in human resources and infrastructure" of the Operational Programme "Growth and Employment" No. 1.1.1.2/VIAA/1/16/161.

\section{Bibliography}

1. Adams, N., Cotella, G., Nunes, R. (2014). Engagement of Territorial Knowledge Communities with European Spatial Planning and the Territorial Cohesion Debate: A Baltic Perspective. European Planning Studies, Volume 22, Issue 4, pp. 712-734. Retrieved: http://dx.doi.org/10.1080/09654313.2013.772735. Accessed: 11.01.2018.

2. CEC - Commission of the European Communities. (1997). The EU Compendium of Spatial Planning Systems and Policies. Luxembourg: Office for Official Publications of the European Communities. p. 192. Retrieved: https://publications.europa.eu/lv/publication-detail/-/publication/059fcedf-d453-4d0d-af36-6f7126698556. Accessed: 09.11.2017.

3. ESPON EGTC 2020. Comparative Analysis of Territorial Governance and Spatial Planning Systems in Europe. Retrieved: https://www.espon.eu/programme/projects/espon-2020/applied-research/comparative-analysisterritorial-governance-and. Accessed: 09.11.2017.

4. European Commission. (2007). Territorial Agenda of the European Union. Towards More Competitive and Sustainable Europe of Diverse Regions. Leipzig. Retrieved: http://ec.europa.eu/regional_policy/sources/policy/what/territorialcohesion/territorial_agenda_leipzig2007.pdf. Access: 19.12.2017.

5. Faludi, A. (2008). European Spatial Research and Planning. Lincoln Institute of Land Policy, p. 304.

6. Radelli, C. M. (2004). Europeanization: solution or problem? European Integration Online Papers, 8 (16). Retrieved: http://eiop. or.at/eiop/texte/2004-016a.htm. Access: 19.12.2017.

7. Reimer, M., Getimis, P. , Blotevogel, H. (Eds.) (2014). Spatial Planning Systems and Practices in Europe: A Comparative Perspective on Continuity and Changes. Routledge, p. 336.

8. Spatial Development Planning Law (2011). Retrieved: http://likumi.lv/doc.php?id=238807 